\title{
Histomorphological Changes in the Peritumoral Zone in Patients with Localized Prostate Cancer as Predictors of Disease Progression
}

\author{
DOI: $10.17691 / \mathrm{stm} 2018.10 .3 .17$
}

Received November 18, 2017

Ph.S. Bova, MD, PhD, Head of Urology, Nephrology and Hemodialysis Center ${ }^{1}$;

A.Yu. Maksimov, MD, DSc, Professor, Deputy Director;

N.S. Karnaukhov, Head of Anatomic Pathology Department2;

O.I. Kit, MD, DSc, Corresponding Member of Russian Academy of Sciences, Professor, Director 2

${ }^{1}$ Regional Hospital No.2, 33, $1^{\text {st }}$ Konnoy Armii St., Rostov-on-Don, 344112, Russia;

${ }^{2}$ Rostov Research Institute of Oncology, 63, 14 ${ }^{\text {th }}$ Liniya St., Rostov-on-Don, 344037, Russia

The aim of the investigation was to study dysplastic, hyperplastic and inflammatory changes in the peritumoral zone and their influence on proliferative activity of tumor cells in patients with localized prostate cancer (PC) after radical prostatectomy.

Materials and Methods. Histomorphological examination of surgical tissue samples from the perifocal zone was carried out using light microscopy in 309 patients with localized PC $\left(\mathrm{T}_{1 \mathrm{c}}-\mathrm{T}_{2 \mathrm{c}} \mathrm{N}_{0} \mathrm{M}_{0}\right)$ after radical surgery. High degree of histopathological differentiation was found in 22 patients (7.1\%), moderate degree in $283(91.6 \%)$ and low degree in 4 patients (1.3\%). Serum prostate-specific antigen concentration was determined by enzyme immunoassay. Proliferative activity of tumor cells was studied using immunohistochemical examination of Ki-67 marker expression in the tumor.

Results. Histomorphological examination of the peritumoral zone made it possible to reveal histopathological processes combined with prostate adenocarcinoma in 257 of $309(83.2 \%)$ patients with localized prostate cancer: nonspecific chronic bacterial prostatitis in $60.2 \%$ of cases, high-grade prostatic intraepithelial neoplasia (PIN-2) in $31.1 \%$, benign hyperplastic processes including sclerosing adenosis and their combinations in $21 \%$.

The most pronounced chronic inflammatory changes in the perifocal zone were observed when prostate adenocarcinoma was combined with PIN-2. The presence of concomitant pathology in the perifocal zone led to no statistically significant change in serum prostate-specific antigen level. Proliferative activity of tumor cells increased in patients with PC when concomitant dysplastic processes in the peritumoral zone were combined with proliferation of stromal components in the prostate gland due to chronic prostatitis and sclerosing adenosis.

Conclusion. Perifocally located PIN-1, PIN-2, chronic prostatitis and sclerosing adenosis increase tumor cell proliferation in prostate adenocarcinoma, thus proving their predictor role.

Key words: prostate cancer; prostate adenocarcinoma; peritumoral zone; prostatic intraepithelial neoplasia; sclerosing adenosis; chronic prostatitis; proliferative activity.

\section{Introduction}

According to the official statement on cancer care in Russia for 2016, the diagnosis of prostate cancer (PC) had the minimum rate of morphological confirmation $(80.2 \%)$ in Rostov region compared to the average rate $(94.7 \%)$ in Russia [1]. In 2015, the rate of morphological verification for $\mathrm{PC}$ diagnosis was also low in 6 regions of the country, including Rostov region (82.1\%) [2]. In recent years, this problematic situation in the region has led to corresponding increase in histological studies in prostate cancer, accumulation of information requiring system analysis. Studying histomorphological changes in prostate preparations obtained during surgical treatment of prostate cancer has high diagnostic value for a particular patient and good prognostic potential regarding common cancer patterns in total data analysis.

All of the above suggests significance of morphological studies in prostate cancer. Given the fact that more than half of the patients with newly verified prostate cancer diagnosis $(56 \%)$ have stage I-II disease [1], specialists' efforts should be aimed at verification of localized forms of the disease and conditions preceding the development of malignant prostate tumors. Not only tumor samples are subjected to morphological examination following radical prostatectomy but also the perifocal zones of the prostate, surgical margin [3]. However, information on specific features of tissues and cells surrounding prostate adenocarcinoma (prostatic intraepithelial neoplasia (PIN), signs of sclerosing adenosis, nonspecific bacterial chronic prostatitis (CP))

Corresponding author: Philip S. Bova, e-mail: alald@inbox.ru 
is rare in the literature [4-6]. However, pathological changes in the peritumoral zone are likely to promote mutagenesis in stromal and epithelial cells, increasing the possibility of mutations and genetic instability in adjacent specific cells [7].

The concept based on the idea that environmental and microenvironmental factors play an important role in tumor emergence and development, recurrence and metastasis formation has existed since 1990. The term "microenvironment" refers to a number of factors characterizing the events within the tumor [8]. Processes occurring in the perilesional tissue of the tumor comprise the notion of "tumor environment" or "peritumoral zone" [9]. Tumor progression in prostate cancer depends on both molecular changes in epithelial cells and numerous changes in the stroma surrounding tissue and cell elements providing the necessary conditions for proliferation, migration, and invasion of cancer cells [10,11].

Studying the relationship between chronic inflammation, fibrosis, dysplasia, hyperplasia in the peritumoral zone and proliferative potential of tumor cells may be useful for understanding the possible causes of early recurrence of malignant tumors.

The aim of the investigation was to study dysplastic, hyperplastic and inflammatory changes in the peritumoral zone and their influence on proliferative activity of tumor cells in patients with localized prostate cancer after radical prostatectomy.

\section{Materials and Methods}

The study was carried out in Urology, Nephrology and Hemodialysis Center of Regional Hospital No.2, Rostovon-Don, in the Department of Oncourology and Anatomic Pathology Department of Rostov Research Institute of Oncology in 2015-2017.

Histomorphological examination of surgical bioptates was carried out in 309 patients with localized PC ( $\mathrm{T}_{1 \mathrm{c}^{-}}$ $\mathrm{T}_{2 \mathrm{c}} \mathrm{N}_{0} \mathrm{M}_{0}$ ) after radical surgery. The age of patients in the general clinical group was $54-79$ years (on average, $65.6 \pm 2.5$ years).

Criteria for inclusion of patients in the study were as follows:

localized PC $\left(T_{1 c}-T_{2 c}\right)$;

availability of data on the preoperative level of prostate-specific antigen (PSA);

histological examination of tumor and peritumoral zone samples;

no distant metastases.

The study complies with the Declaration of Helsinki (2013) and was approved by Ethics Committee of Rostov Research Institute of Oncology. Written informed consent was obtained from all patients.

Distribution of patients based on the clinical stage of PC was as follows: patients with $\mathrm{T}_{1 \mathrm{c}}-28(9.1 \%) ; \mathrm{T}_{2 \mathrm{a}}-$ 33 (10.7\%); $\mathrm{T}_{2 b}-89(28.8 \%) ; \mathrm{T}_{2 c}-159$ (51.5\%). High degree of histopathological differentiation (less than
7 Gleason scores) was found in 22 patients $(7.1 \%)$, moderate degree (7 Gleason scores) in $283(91.6 \%)$ and low degree (more than 7 Gleason scores) in 4 patients $(1.3 \%)$.

After radical prostatectomy, the material obtained by the surgeon was placed in $4 \%$ buffered formalin solution and taken immediately to anatomic pathology department where it was stored no more than $24 \mathrm{~h}$. For morphological examination, the pathologist formed samples of tumor tissue (minimum 3 pieces), the peritumoral zone $(2 \mathrm{~cm}$ and more off the tumor, from both lobes of the gland) by cutting cone-shaped pieces $1.0 \times 0.5 \mathrm{~cm}$ in size. Then tissue segments were cut into 15-20 slices of $0.3 \mathrm{~mm}$ thickness.

Microscopic examination was performed to determine the histological type of tumor, the degree of histopathological differentiation. In all patients, the histological type of tumor was represented by adenocarcinoma. Based on the results of histological examination of peritumoral bioptates, the patients were divided into subgroups with the following pathologies: PIN-2, PIN-1, benign prostatic hyperplasia (BPH), CP.

To perform histological examination by light microscopy, gland tissue slices were fixed in $10 \%$ neutral buffered formalin solution (Lilly's Formalin) with $\mathrm{pH} 7.4$, then paraffin-embedded using the standard technique. Serial 3-5 $\mu \mathrm{m}$ thick sections were deparaffinized using the standard procedure, stained with hematoxylin and eosin. The samples were examined under TOPIC-T light microscope (CETI, Netherlands).

The following histological classification of prostatitis was used in the study: mild, moderate and severe degree (the North American Chronic Prostatitis Collaborative Research Network and the International Prostatitis Collaborative Network, 2001) [12]. Moderate and severe dysplasia (PIN-2) was classified as highgrade prostatic intraepithelial neoplasia, mild dysplasia (PIN-1) - as low-grade one.

Prior to surgery, serum PSA concentration was measured in all patients by enzyme immunoassay using Multiscan P2 photometer (Thermo Fisher Scientific Inc., Finland).

Immunohistochemical examination was performed according to the standard protocol. The prepared serial sections were mounted on poly-L-lysine coated glass. Deparaffinization was carried out in a thermostat at $60^{\circ} \mathrm{C}$ for an hour. After immersion in xylene, the sections were rehydrated in a graded series of alcohol with decreasing concentrations for $15 \mathrm{~min}$. Antigen retrieval was performed by heat-induced retrieval method in $0.01 \mathrm{M}$ citrate buffer using mini-autoclave EnVision/HRP (Dako Cytomation, Denmark). Endogenous peroxidase activity was blocked using $3 \%$ hydrogen peroxide for $10 \mathrm{~min}$. In this study, we used mouse monoclonal antibodies to Ki-67 protein (1:200, Diagnostic Biosystems, Spain).

Microscopic examination was performed using light microscope Axioskop 40 (Carl Zeiss, Germany); 10x eyepiece, 5x, 10x, 20x, 40x, 100× lenses. At the first 
stage, loci with the greatest number of "positive" cells were detected. The cells with unmistakable nuclei color were considered positive. Ki-67 index was calculated as the ratio of the number of cells with intense nuclear reaction to the total cell number (at least 300 cells). If Ki67 index was less than or equal to $25 \%$, this situation was assessed as 1 score, 26 to $50 \%$ - as 2 scores, 51 to $75 \%$ - as 3 scores and 76 to $100 \%$ - as 4 scores [13].

Statistical data processing was performed using Statistica 10.0 (StatSoft, USA) software. Quantitative parameters were presented as mean value and standard error of the mean. Pearson's $X^{2}$ test, Fisher's exact test were used to analyze the differences in proportions. Nonparametric Mann-Whitney test was used to assess the difference between the means.

\section{Results}

No histological changes in the peritumoral zone were found in 52 of 309 patients (16.8\%) with localized prostate cancer. Histopathological processes combined with adenocarcinoma were observed in 257 patients (83.2\%), their distribution is shown in Table 1.

Chronic inflammatory changes in the perifocal zone with clusters of lymphocytes, plasma cells, and macrophages in the stroma, reactive nuclear atypia were more common than other pathological processes (in 186 of $257,72.4 \%$ ). The proportion of severe CP increased in line $\mathrm{PC}<\mathrm{PC}+\mathrm{BPH}<\mathrm{PC}+\mathrm{PIN}-2$; the proportion of moderate $\mathrm{CP}$ increased in line $\mathrm{PC}+\mathrm{PIN}-$ $2<\mathrm{PC}+\mathrm{BPH}=\mathrm{PC}$; the proportion of mild CP increased in line $\mathrm{PC}+\mathrm{PIN}-2<\mathrm{PC}<\mathrm{PC}$ (see the Figure).

Thus, the most pronounced chronic inflammatory changes in the perifocal zone were observed when both prostate adenocarcinoma and PIN-2 were revealed.

PIN-2 came second in terms of prevalence in the peritumoral zone: in 96 of 257 samples (37.4\%). Moreover, in $27.6 \%$ (71 out of 257 ) of patients with localized PC, PIN-2 was detected against the background of chronic inflammatory changes in the prostate gland (see Table 1). Concomitant benign hyperplastic processes were revealed in $25.3 \%$ of cases (65 out of 257), BPH being represented by sclerosing adenosis in 11 out of 65 (17\%). Microscopically, sclerosing adenosis looked like a focus of small, closely adjacent proliferating glands surrounded by a marked spindle-cell stromal component. The cytoplasm of glandular cells was scarce, acidophilic, cell nuclei were small, monomorphic, moderately colored, without

\section{Table 1}

\section{Distribution of morphological changes} in the peritumoral zone in patients with localized prostate cancer $(n=257)$ after radical prostatectomy

\begin{tabular}{lcc}
\hline \multicolumn{1}{c}{$\begin{array}{c}\text { Histopathological processes } \\
\text { in the peritumoral zone }\end{array}$} & $\begin{array}{c}\text { Absolute } \\
\text { number }\end{array}$ & $\%$ \\
\hline PIN-2 & 96 & 37.4 \\
\hline PIN-1 & 29 & 11.3 \\
\hline CP: & 186 & 72.4 \\
only CP & 67 & 26.1 \\
combination with other background & 119 & 46.3 \\
processes & 65 & 25.3 \\
\hline BPH, & 11 & 4.3 \\
including sclerosing adenosis & 71 & 27.6 \\
\hline PIN-2 + CP & 8 & 3.1 \\
\hline PIN-1 + CP & 18 & 7.0 \\
\hline PIN-2 + PIN-1 + CP & 40 & 15.6 \\
\hline BPH + CP & & \\
\hline
\end{tabular}

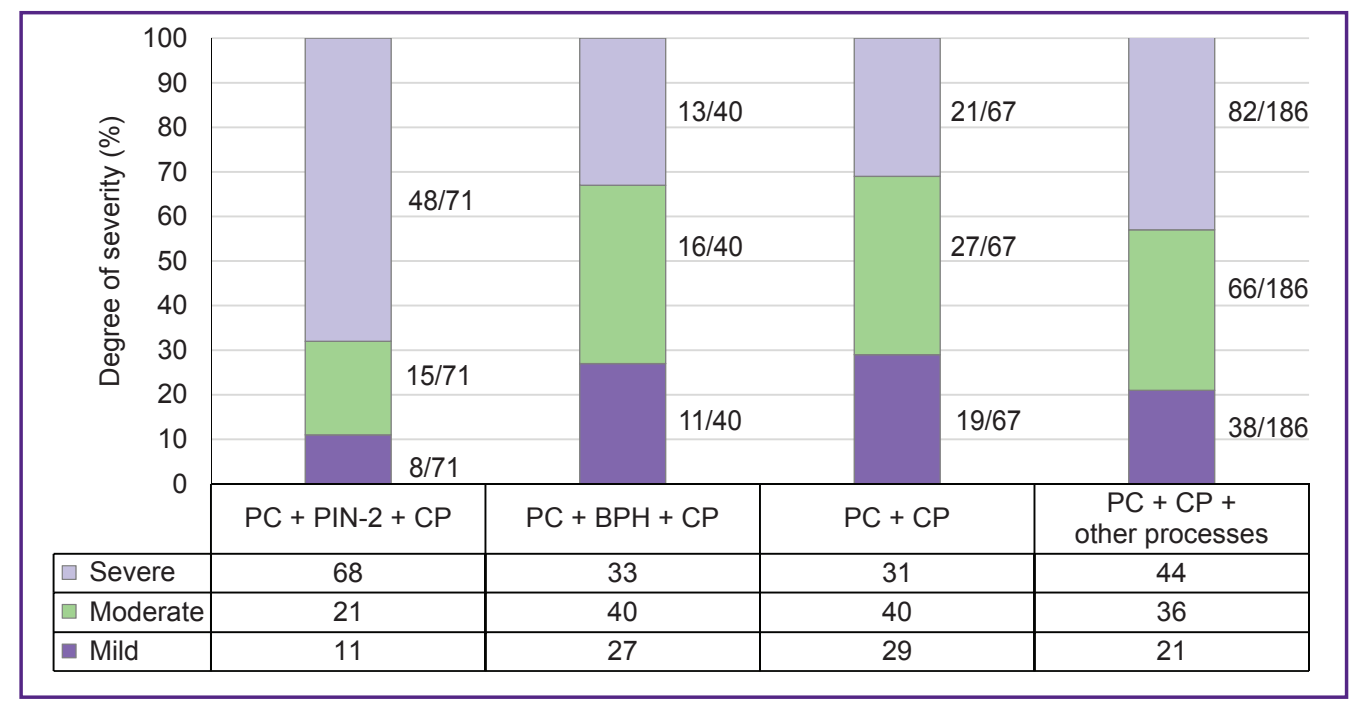

Distribution of patients with prostate cancer combined with various histopathological changes in the peritumoral zone based on chronic prostatitis severity

The table shows percentages, absolute numbers are next to bar charts 
cellular polymorphism. Constant presence of basal cell layer around all glands was characteristic. Amyloid corpuscles, crystalloids, occasional mitotic figures, and solid foci were observed as inconstant features.

In patients with localized PC, the presence of combined pathology in the perifocal zone led to no statistically significant change in mean serum PSA values, which required more detailed frequency analysis and comparison of proportions (Table 2).

Frequency analysis showed that the number of patients with serum PSA concentration over $21 \mathrm{ng} /$ $\mathrm{ml}$ was higher when PC was combined with PIN-2 and $\mathrm{CP}$ in the perifocal region as compared to isolated adenocarcinoma ( 16 vs $2 \%$ at $p=0.013$ ).

Immunohistochemical examination with antibodies to $\mathrm{Ki}-67$ is conventionally used to assess proliferative

Table 2

The level of serum prostate-specific antigen in patients with localized prostate cancer and concomitant pathology (absolute number/\%)

\begin{tabular}{|c|c|c|c|c|}
\hline \multirow{2}{*}{$\begin{array}{l}\text { Combined } \\
\text { histopathological processes }\end{array}$} & \multicolumn{4}{|c|}{ Serum prostate-specific antigen (ng/ml) } \\
\hline & $4-10$ & $11-20$ & $\geq 21$ & $M \pm m$ \\
\hline $\begin{array}{l}\text { PC without peritumoral changes } \\
\text { (control) }(n=52)\end{array}$ & $2 / 4$ & $49 / 94$ & $1 / 2$ & $12.5 \pm 1.6$ \\
\hline$P C+P I N-2(n=96)$ & $1 / 1$ & $90 / 94$ & $5 / 5$ & $12.1 \pm 1.3$ \\
\hline$P C+P I N-1(n=29)$ & $3 / 10$ & $22 / 76$ & $4 / 14$ & $12.6 \pm 1.1$ \\
\hline$P C+C P(n=67)$ & $2 / 3$ & $61 / 91$ & $4 / 6$ & $11.9 \pm 0.9$ \\
\hline$P C+B P H(n=54)$ & $1 / 2$ & $50 / 93$ & $3 / 5$ & $12.2 \pm 1.0$ \\
\hline$P C+$ sclerosing adenosis $(n=11)$ & $0 / 0$ & $10 / 91$ & $1 / 9$ & $12.4 \pm 0.7$ \\
\hline$P C+P I N-2+C P(n=71)$ & $3 / 4$ & $57 / 80$ & $11 / 16^{*}$ & $13.8 \pm 1.8$ \\
\hline
\end{tabular}

Note: * statistically significant difference of values with control, $p=0.013$ (by Fisher criterion); $\mathrm{M}$ - mean and $\mathrm{m}$ - standard error of the mean. activity of tumor cells, including those in PC [13]. Ki-67 belongs to regulatory proteins, its expression coincides with the entry of cells into mitosis. For the largest number of patients with localized PC, Ki-67 expression was assigned 2 scores (26-50\% of colored cells) regardless of combined pathology in the peritumoral zone (Table 3).

However, only when adenocarcinoma was combined with PIN-2, the number of cells with Ki-67 expression exceeded $50 \%$ and was ranked on a scale of $3(8 \%)$ and $4(1 \%)$ scores. When there were no changes in the perifocal zone, the score of 1 was observed less often $(p<0.0001)$ after Ki-67 staining in patients with a combination of PC + PIN-2, the score of 2 was more frequent $(p<0.0001)$, in $9 \%$ of cases the samples were assigned 3-4 scores, compared to the control. In combination of $\mathrm{PC}+\mathrm{PIN}-2+\mathrm{CP}$, the number of tumor cells expressing $\mathrm{Ki}-67$ exceeded $50 \%$ (3-4 scores) in $10 \%$ of cases. Consequently, proliferative activity of tumor cells increased when PC occurred simultaneously with PIN-2.

The average semi-quantitative score of Ki-67 expression in tumor cells was significantly higher $(p<0.05)$ when PC was combined with PIN-2 $(2.09 \pm 0.04$ scores $)$ or $\mathrm{PC}+\mathrm{PIN}-2+\mathrm{CP}(2.11 \pm 0.04$ scores) as compared to isolated PC $(1.60 \pm 0.07$ scores $), \mathrm{PC}+\mathrm{PIN}-1$ (1.66 \pm 0.09 scores), PC + CP $(1.72 \pm 0.06$ scores), PC + BPH (1.78 \pm 0.06 scores) (Table 4).

Ki-67 expression score was almost similar in patients with $\mathrm{PC}+\mathrm{PIN}-2$ and PC + sclerosing adenosis.

Thus, tumor cell proliferation increases in patients with PC when concomitant dysplastic processes in the peritumoral

Table 3

Distribution of patients with prostate cancer based on the degree of Ki-67 expression in tumor cells with account of combined pathology in the peritumoral zone (absolute number/\%)

\begin{tabular}{|c|c|c|c|c|}
\hline \multirow{2}{*}{$\begin{array}{l}\text { Combined } \\
\text { histopathological processes }\end{array}$} & \multicolumn{4}{|c|}{ Ki-67 expression (scores) } \\
\hline & 1 & 2 & 3 & 4 \\
\hline $\begin{array}{l}\text { PC without peritumoral changes } \\
\text { (control) }(n=52)\end{array}$ & $21 / 40$ & $31 / 60$ & $0 / 0$ & $0 / 0$ \\
\hline$P C+P I N-2(n=96)$ & $1 / 1(p<0.0001)$ & $86 / 90(p<0.0001)$ & $8 / 8(p=0.05)$ & $1 / 1$ \\
\hline$P C+P I N-1(n=29)$ & $10 / 34$ & $19 / 66$ & $0 / 0$ & $0 / 0$ \\
\hline$P C+C P(n=67)$ & $19 / 28$ & $48 / 72$ & $0 / 0$ & $0 / 0$ \\
\hline$P C+B P H(n=54)$ & $12 / 22$ & $42 / 78$ & $0 / 0$ & $0 / 0$ \\
\hline$P C+$ sclerosing adenosis $(n=11)$ & $2 / 18$ & $7 / 64$ & $2 / 18$ & $0 / 0$ \\
\hline$P C+P I N-2+C P(n=71)$ & $0 / 0$ & $64 / 90(p=0.0002)$ & $6 / 9(p=0.038)$ & $1 / 1$ \\
\hline
\end{tabular}

Note: $p$ - statistically significant difference of values with isolated prostate cancer (control). 
Table 4

The score and cross-group comparative analysis of Ki-67 expression in tumor cells of patients with prostate cancer based on concomitant pathology in the peritumoral zone

\begin{tabular}{|c|c|c|c|c|c|c|c|c|}
\hline \multirow{2}{*}{ No } & \multirow{2}{*}{$\begin{array}{l}\text { Combined } \\
\text { histopathological processes }\end{array}$} & \multirow{2}{*}{$M \pm m$} & \multicolumn{6}{|c|}{$p$ between groups } \\
\hline & & & 1 & 2 & 3 & 4 & 5 & 6 \\
\hline 1 & $\begin{array}{l}\text { PC without peritumoral changes } \\
\text { (control) }(n=52)\end{array}$ & $1.60 \pm 0.07$ & & & & & & \\
\hline 2 & $P C+P I N-2(n=96)$ & $2.09 \pm 0.04$ & 0.00007 & & & & & \\
\hline 3 & $P C+P I N-1(n=29)$ & $1.66 \pm 0.09$ & 0.66 & 0.001 & & & & \\
\hline 4 & $P C+C P(n=67)$ & $1.72 \pm 0.06$ & 0.26 & 0.0002 & 0.635 & & & \\
\hline 5 & $P C+B P H(n=54)$ & $1.78 \pm 0.06$ & 0.11 & 0.004 & 0.359 & 0.563 & & \\
\hline 6 & $P C+$ sclerosing adenosis $(n=11)$ & $2.0 \pm 0.19$ & 0.087 & 0.704 & 0.173 & 0.219 & 0.345 & \\
\hline 7 & $P C+P I N-2+C P(n=71)$ & $2.11 \pm 0.04$ & 0.00008 & 0.853 & 0.001 & 0.001 & 0.003 & 0.628 \\
\hline
\end{tabular}

zone are combined with proliferation of stromal components in the prostate gland, which is likely to affect the time of cancer recurrence later on.

\section{Discussion}

The work focuses on the results of histomorphological examination of pathological processes occurring in the perifocal zone simultaneously with prostate adenocarcinoma. It has been found that the signs of CP $(72.4 \%)$, PIN-2 (37.4\%) and their combinations $(27.6 \%)$ are more common in the areas unaffected by the tumor. According to other authors, the combination of adenocarcinoma and PIN has been found in $40-73 \%$ of patients with verified $\mathrm{PC}$ during histological examination of prostate bioptates [4, 5], PC and CP - in 86.2\% [14]. Certainly, the fact of detecting concomitant pathology has not been the main goal. The main thing is to know the consequences of such association for the course of the underlying disease. There are no research papers in this field, only prospective studies of consecutive relationship between background pathological processes in the gland and PC [15]. For example, chronic inflammation in the prostate gland is associated with stromal fibrosis providing the background for the development of proliferative inflammatory atrophy, a precursor to PIN and PC [16].

At present, there is evidence in the literature that the foci of proliferative inflammatory atrophy have higher proliferative activity, increased expression of Ki67 proliferation marker as compared to the epithelium surrounding the tumor and normal epithelium [17]. Therefore, such atrophy is considered to be a variant of regeneration and the foci themselves may be called "regenerative". In terms of proliferation, they are comparable to PIN phenotype [18].

In our work, assessment of Ki-67 expression shows that the presence of PIN-2 and PIN-2 in combination with $\mathrm{CP}$ in the peritumoral zone is accompanied by increased proliferative activity of adenocarcinoma cells. Sclerosing adenosis is an atypical variant of BPH. The incidence of this pathology in resection of the prostate for $\mathrm{BPH}$ is $2 \%$ [18]. In our study, sclerosing adenosis was found in $4.3 \%$ of cases (11 out of 257) and in 17\% of all BPH cases (11 out of 65). The combination of sclerosing adenosis and PC was accompanied by increasing proliferative activity of adenocarcinoma cells compared to the control group, though the tendency failed to reach statistical significance $(p=0.087)$. Insufficient number of cases of simultaneous PC and sclerosing adenosis in the peritumoral zone requires collecting relevant information to investigate further the relationship between features.

\section{Conclusion}

In patients with prostate cancer, it is appropriate to perform histological examination of both tumor bioptate and perifocal zone as the revealed correlation between histological changes in the peritumoral zone and proliferative activity of tumor cells is a predictor of cancer progression.

Study funding. This study was not supported by any financial sources.

Conflict of interests. The authors have no conflict of interests to disclose.

\section{References}

1. Sostoyanie onkologicheskoy pomoshchi naseleniyu rossii $v 2016$ godu [The state of oncological care for the population of Russia in 2016]. Pod red. Kaprina A.D., Starinskogo V.V., Petrovoy G.V. [Kaprin A.D., Starinskiy V.V., Petrova G.V. (editors)]. Moscow: MNIOI im. P.A. Gertsena; $2017 ; 236 \mathrm{p}$.

2. Sostoyanie onkologicheskoy pomoshchi naseleniyu rossii $v 2015$ godu [The state of oncological care for the population of Russia in 2015]. Pod red. Kaprina A.D., Starinskogo V.V., Petrovoy G.V. [Kaprin A.D., Starinskiy V.V., 
Petrova G.V. (editors)]. Moscow: MNIOI im. P.A. Gertsena; 2017; 236 p.

3. Lozhkin E.A., Suhanov S.A., Kiryanov N.A. New criteria of morphological assessment of the prognosis of the prostate cancer. Uralskiy meditsinskiy zhurnal 2017; 4(148): 70-72.

4. McNeal J.E. Origin and development of carcinoma in the prostate. Cancer 1969; 23(1): 24-34, https://doi.org/ 10.1002/1097-0142(196901)23:1<24::aid-cncr2820230103> 3.0.co;2-1.

5. Bostwick D.G. Progression of prostatic intraepitelial neoplasia to early invasive adenocarcinoma. Eur Urol 1996; 30(2): 145-152, https://doi.org/10.1159/000474164.

6. Allina D.O., Andreeva lu.lu., Zavalishina L.E., Kekeeva T.V., Frank G.A. High-grade prostatic intraepithelial neoplasia: state-of-the-art. Arhiv patologii 2015; 77(1): 69-74.

7. Gorbunova E.N., Davydova D.A., Krupin V.N. Chronic inflammation and fibrosis as risk factors of the prostatic intraepithelial neoplasia (PIN) and prostate cancer. Sovremennye tehnologii v medicine 2011; 1: 79-83.

8. lijima J., Konno R., Itano N. Inflammatory alterations of the extracellular matrix in the tumor microenvironment. Cancers 2011; 3(3): 3189-3205, https://doi.org/10.3390/ cancers 3033189 .

9. Allen M., Jones L.J. Jekyll and Hyde: the role of the microenvironment on the progression of cancer. J Pathol 2011: 223(2): 162-176, https://doi.org/10.1002/path.2803.

10. Dennis L.K., Lynch C.F., Torner J.C. Epidemiologic association between prostatitis and prostate cancer. Urology 2002; 60(1): 78-83, https://doi.org/10.1016/s00904295(02)01637-0.

11. Corn P.G. The tumor microenvironment in prostate cancer: elucidating molecular pathways for therapy development. Cancer Manag Res 2012; 4: 183-193, https:// doi.org/10.2147/cmar.s32839.

12. Nickel J.C., True L.D., Krieger J.N., Berger R.E., Boag A.H., Young I.D. Consensus development of a histopathological classification system for chronic prostatic inflammation. BJU Int 2001; 87(9): 797-805, https://doi. org/10.1046/j.1464-410x.2001.02193.x.

13. Kovylina M.V., Prilepskaya E.A., Sergeiko I.P., Moiseenko T.N., Kolantarev K.B., Govorov A.V., Pushkar D.Yu. Prognostic value of the immunohistochemical markers Ki-67 and p53 after radical prostatectomy. Onkourologija 2014; 1 : 49-52.

14. Platz E.A., Kulac I., Barber J.R., Drake C.G., Joshu C.E., Nelson W.G., Lucia M.S., Klein E.A., Lippman S.M., Parnes H.L., Thompson I.M., Goodman P.J., Tangen C.M., De Marzo A.M. A prospective study of chronic inflammation in benign prostate tissue and risk of prostate cancer: linked PCPT and SELECT cohorts. Cancer Epidemiol Biomarkers Prev 2017; 26(10): 1549-1557, https://doi. org/10.1158/1055-9965.epi-17-0503.

15. Davidsson S., Fiorentino M., Andrén O., Fang F., Mucci A., Varenhorst E., Fall K., Rider J.R. Inflammation, focal atrophic lesions, and prostatic intraepithelial neoplasia with respect to risk of lethal prostate cancer. Cancer Epidemiol Biomarkers Prev 2011; 20(10): 2280-2287, https://doi. org/10.1158/1055-9965.epi-11-0373.

16. Leone A., Gershman B., Rotker K., Butler C., Fantasia J., Miller A., Afiadata A., Amin A., Zhou A., Jiang Z., Sebo T., Mega A., Schiff S., Pareek G., Golijanin D., Yates J., Karnes R.J., Renzulli J. Atypical small acinar proliferation (ASAP): is a repeat biopsy necessary ASAP? A multiinstitutional review. Prostate Cancer Prostatic Dis 2016; 19(1): 68-71, https://doi.org/10.1038/pcan.2015.52.

17. Davidsson S., Carlsson J. Prostate cancer and inflammation: the role of miRNAs. EMJ Oncol 2013; 1: 56-60.

18. Kuroda N., Katto K., Ohtsuki Y., Hes O., Michal M., Inoue K., Ohara M., Mizuno K., Lee G.H. Hybrid sclerosing adenosis and basal cell hyperplasia of the prostate. Med Mol Morphol 2010; 43(4): 226-230, https://doi.org/10.1007/s00795009-0449-8. 